\title{
Repatriação e Restituição de bens culturais: caminhos possíveis
}

\author{
Repatriación y restitución de bienes culturales: caminos posibles
}

Repatriation and Restitution of Cultural Property: possible paths

\author{
Karine Lima da Costa $^{1}$ \\ Kimberly Terrany Alves Pires ${ }^{2}$
}

\section{Introdução}

Desde 2017, o presidente da França, Emmanuel Macron, demonstrou o interesse em devolver temporária ou permanentemente alguns objetos da África subsaariana que se encontram em museus franceses. Para isso, ele encomendou um relatório que analisou o histórico e a viabilidade de retorno das peças, elaborado pela historiadora francesa Bénédicte Savoy e pelo economista senegalês Felwine Sarr. Após a publicação do documento, em novembro de 2018, a primeira medida tomada pela França foi a devolução de vinte e seis objetos roubados do Benin que estão no Museu de Quai Branly, em Paris³.

Essa medida é uma das mais importantes dentro do cenário internacional sobre o tema da repatriação de bens culturais, que nos últimos anos vem sendo discutido amplamente, como um dos resultados diretos dos processos de descolonização (GAY, 2013). Nesse contexto, os objetos da cultura material que foram retirados de seus territórios originais em século passados ganharam destaque ao serem reivindicados por diferentes grupos sociais:

O passado, configurado pelo patrimônio arqueológico, assenta-se num campo minado. É que o passado ainda não passou. O patrimônio arqueológico torna-o palpável, tangível. O passado, materializado pela cultura material, é sempre institucionalizado. Compõe as relações de força das sociedades. As representações culturais sobre o passado articulam as táticas de governo, as estratégias de poder, de cultura e sociedade (FERREIRA, 2009, p. 70).

A Arqueologia, considerada uma área multidisciplinar, surgiu no decorrer do século XIX, paralela ao desenvolvimento do imperialismo e do nacionalismo (s). Durante esse período, estudiosos e diplomatas eram enviados a diferentes territórios para cumprir uma série

\footnotetext{
${ }^{1}$ Doutora em História pela Universidade Federal de Santa Catarina; Porto Alegre, Rio Grande do Sul, Brasil; kakalima1@gmail.com

${ }^{2}$ Mestranda em Museologia e Patrimônio pela Universidade Federal do Rio Grande do Sul; Porto Alegre; Rio Grande do Sul; Brasil; kimterrany@gmail.com

${ }^{3}$ Disponível em: https://www.dw.com/pt-br/fran\%C3\%A7a-vai-devolver-26-obras-de-arte-ao-benin/a-46433723 Acesso em: 23 dez. 2019.
} 
de funções, dentre elas, a recolha de objetos e monumentos antigos para serem transferidos a outros países. Esses itens compõem os acervos dos primeiros museus europeus e atualmente estão sendo alvo de pedidos de repatriação.

De acordo com as premissas conceituais, o dicionário Oxford ${ }^{4}$ descreve o verbo repatriar (repatriate) como o "retorno de alguém ao seu próprio país" ou o "envio de dinheiro ao seu próprio país". Já o substantivo restituição (restitution) pode significar "a restauração de algo perdido ou roubado" ou "recompensa por lesão ou perda". No campo museológico, trabalhamos com o conceito de "desmusealização" de acervos, referente "[...] aos casos mais simples de devolução de peças a seus contextos originais" "(MENESES, 1993, p. 214). Nesse sentido, optamos por utilizar o termo repatriação quando mencionarmos as reivindicações entre diferentes países ao invés de restituição, utilizado para se referir a deslocamentos dentro do mesmo território ou como medida compensatória (COSTA, 2019).

A partir do estudo de caso específico da Grécia e do Egito - países que há anos mobilizam a discussão em torno da repatriação de bens culturais -, objetivamos sinalizar alguns caminhos possíveis para a resolução desses conflitos no âmbito museológico, dado que algumas instituições ainda mantêm uma postura contrária em relação à devolução desses bens.

\section{Grécia}

O pedido oficial mais antigo de devolução de uma coleção material remonta aos Mármores do Parthenon, que desde a década de 1980, estão sendo reivindicados pela Grécia. O movimento surgiu a partir da solicitação da ex-ministra Melina Mercouri, posteriormente responsável pela criação da Fundação Melina Mercouri, que atualmente realiza ações de apoio ao Museu da Acrópole pela reunificação da coleção. No início do século XIX, as peças foram negociadas e transportadas para a Inglaterra por Lord Elgin, embaixador britânico. Em seguida foram vendidas ao governo inglês, que as encaminhou para o Museu Britânico, onde permanecem atualmente.

O principal modelo institucional de museus se consolidou no século XIX, tendo como expoentes do período a constituição do Museu do Louvre, em Paris e do Museu Britânico, em Londres, os quais apresentam acervos oriundos das mais variadas e distintas partes do mundo, frutos de um processo de espoliação e colonização. O reconhecimento pela política preservacionista e pesquisas científicas desenvolvido a partir destas instituições é inegável.

\footnotetext{
${ }^{4}$ Disponível em: https://www.lexico.com/definition/repatriate Acesso em: 10 dez. 2019.

5 A desmusealização pode ser considerada o oposto do processo de "musealização", definida como"[...] uma série de ações sobre os objetos, quais sejam: aquisição, pesquisa, conservação, documentação e comunicação" (CURY, 2005, p. 26).
} 
Porém, nestes novos tempos cabe tencionar outras questões de cunho social e de representatividade destas coleções.

Neste contexto, palavras como "coisa", objeto, bens, valoração, autenticidade, entre outras, auxiliam no entendimento dos valores envolvidos na formação de uma coleção de interesse mundial. De forma bastante abrangente, de acordo com Deetz (1977, p. 7 apud PEARCE, 1992, p .4), “cultura material é todo aquele segmento do ambiente físico humano o qual é propositalmente formado por ele de acordo com um plano culturalmente ditado". Este objeto inteiro ou fragmentado é selecionado e deixa o mundo das coisas naturais e utilitárias para receber outras dimensões de valores. O valor econômico é sempre pautado como um grande interesse, ainda mais em se tratando de peças de antigas e artísticas. Nessa perspectiva, conforme a autora, se tornam rasos os valores se não considerarem a dimensão social e cultural associadas ao material (PEARCE, 1992). Assim, esta coleção aborda uma complexa cadeia de valores atribuídos a partir do contexto social que se encontram, especialmente pelo seu poder de representatividade, seja em um discurso de universalidade, como no caso do Museu Britânico ou nacionalidade, no caso do Museu da Acrópole.

A discussão em torno da propriedade dos mármores vem ao encontro das reflexões contemporâneas do campo museológico, como a busca pela democratização, conforme apontou Cristina Bruno (2006). Este é um dos argumentos mais utilizados para a manutenção das peças em território inglês, reconhecendo que o Museu Britânico figura entre os dez museus mais visitados do mundo em algumas pesquisas. No entanto, não se podem ignorar os apoios políticos e de marketing que fundamentam essas características elitistas e a reprodução de discursos dominantes.

Durante muito tempo a falta de um espaço adequado para a exposição e a guarda dessa coleção na Grécia foi uma justificativa aceitável para a sua permanência em Londres, contudo, a partir de 2009 essa situação passou por mudanças significativas com a inauguração do Museu da Acrópole, em Atenas. Nesse mesmo ano, a Grécia refez o pedido de devolução das esculturas ao Museu Britânico, que continuou com a sua posição de legalidade do direito de propriedade, complementando que tais monumentos pertencem todos e que a sua visitação no museu é totalmente gratuita, podendo ser estudada também online ${ }^{6}$.

Nesta perspectiva, as práticas museológicas colaboram com a sociedade “[...] na identificação de suas referências culturais, na visualização de procedimentos

\footnotetext{
${ }^{6}$ Essas informações estão disponíveis no site do Museu Britânico, que enfatiza a retirada legal dos mármores no século XIX e reafirma a sua posição contrária aos pedidos de repatriação. Disponível em: http://www.britishmuseum.org/about_us/news_and_press/statements/parthenon_sculptures.aspx Acesso em 04 abr. 2017.
} 
preservacionistas que as transformem em herança patrimonial e na implementação de processos comunicacionais" (BRUNO, 2006, p. 07). Neste caso, a compreensão da herança patrimonial elege, por exemplo, a Acrópole como um Patrimônio Mundial, que tem como requisito um "Valor Universal Excepcional”, conceituado como "[...] um significado cultural e/ou natural que é excepcional ao ponto de transcender as fronteiras nacionais e ter importância comum para as gerações presentes e futuras de toda a humanidade" (GESTÃO..., 2016, p.40). Este patrimônio agora transborda o seu cenário nacional e ganha representação de uma identidade coletiva e universal.

No entanto, nesta disputa a Grécia desenvolveu uma política de conscientização junto à população local e à comunidade internacional, visando a criação de uma identidade cultural com o auxílio do novo espaço museal: o Museu da Acrópole. Conforme Guarnieri ([s.a.] 2010, p.121), “o patrimônio cultural é questão de consciência histórica" e, desta forma, os gregos foram sensibilizados na defesa de sua herança cultural. Assim, podemos pensar no "poder dos objetos" através da representação e da produção da identidade de uma nação:

"[...] nós usamos objetos para fazer declarações sobre nossa identidade, nossos objetivos, e mesmo nossas fantasias. Através dessa tendência humana, de atribuir significados aos objetos, aprendemos desde tenra idade que as coisas que usamos veiculam mensagens sobre quem somos e sobre quem buscamos ser. (...). Estamos intimamente envolvidas com objetos que amamos, desejamos, com os que presenteamos ou outros. Marcamos nossos relacionamentos com objetos (...) Através dos objetos fabricamos nossa autoimagem, cultivamos e intensificamos relacionamentos. Os objetos guardam ainda o que no passado é vital para nós. (...). Não apenas nos fazem retroceder no tempo, como também tornam-se os tijolos que ligam o passado ao futuro" (WEINER, 1987 apud DOHMANN, 2013, p. 159).

O Museu da Acrópole - avaliado como uma instituição com padrões de excelência -, impressiona os críticos desde o seu projeto arquitetônico, pois dialoga com o espaço das ruínas da Acrópole e com os sítios arqueológicos locais, utilizando a transparência e os espaços vazios em diversas áreas. Sua principal galeria, “o Parthenon”, está posicionada em consonância com a mesma coordenada espacial do templo que se encontra no topo da colina, o que permitiu a manutenção a partir de uma cenografia dos espaços originais das peças. Além disso, a sua expografia explicita as ausências, propositalmente pensadas para demonstrar as lacunas da história daquele espaço, possibilitando ao público a identificação das peças que não se encontram no território grego. A partir dessas estratégias expográficas o museu aposta na construção de um discurso sensível e legitimador. 


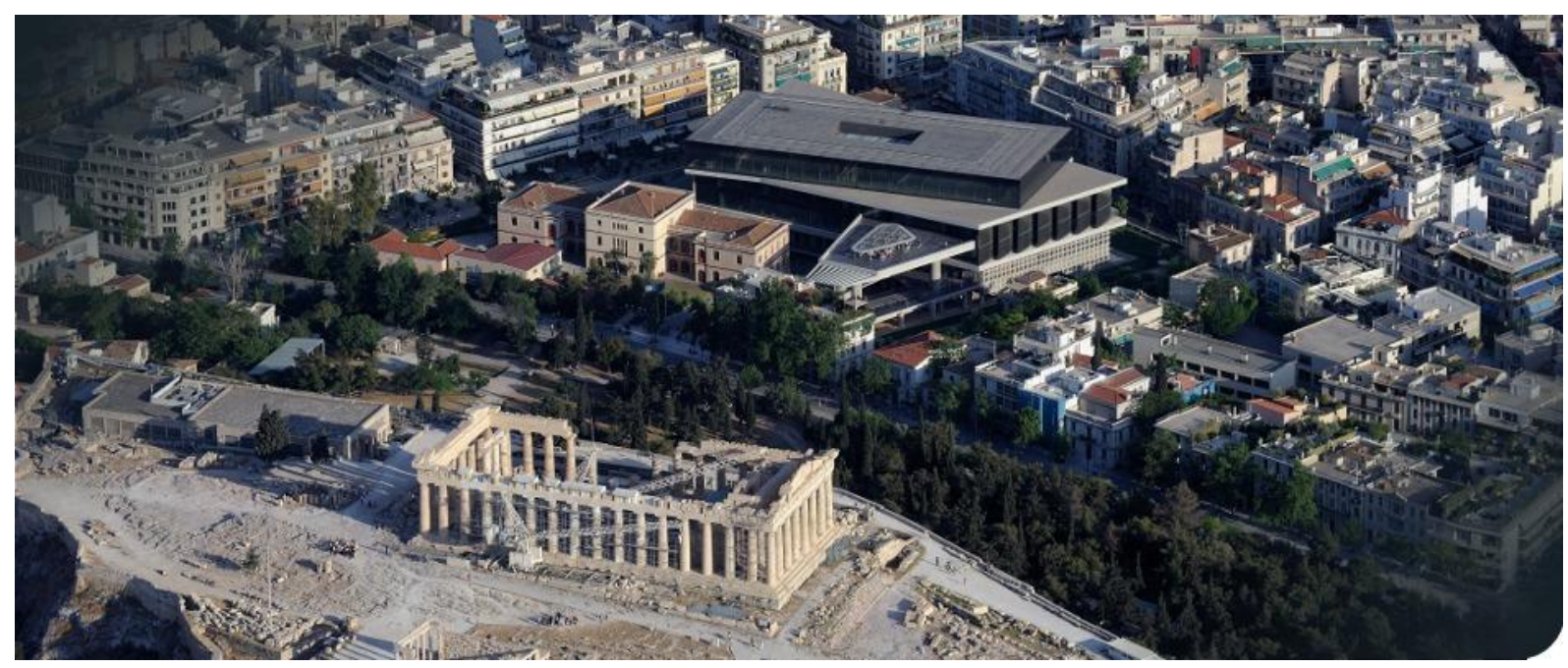

Figura 1 - Museu da Acrópole, Atenas, Grécia.

Fonte: Acervo Digital ${ }^{7}$.

Em oposição, o Museu Britânico apresenta a coleção dos Mármores sem lacunas, como se não houvesse uma ordenação ou como se elas não fizessem parte de um conjunto maior de um programa escultural, que retrata uma história mitológica grega. Neste contexto a permanência desta coleção está validada no discurso da exibição das coleções universais, que ainda se ratificam pelo grande público que as freqüenta e seus gestores. Nessa perspectiva percebe-se a instituição como uma incentivadora de expedições arqueológicas e negociações de artefatos inéditos, no mercado dos bens culturais. Ainda que não seja um discurso claramente aberto, "a visão de domínio e colonialismo também atravessa a importância da manutenção do acervo neste local. A luta pela permanência dos Mármores do Parthenon, fundamentada no domínio das civilizações, ele reitera sua importância como instituição secular, que "salvou" a história do mundo" (PIRES, 2017, p. 78).

Conforme Dohmann (2013), podemos afirmar que essa coleção recebe valores simbólicos distintos de acordo com a instituição que a apresenta, ao qual se relaciona com os contextos em que está inserida, superando a sua função prática e ganhando um sentido que transborda o seu uso. Na perspectiva grega, a relação entre objeto e contexto, permitida a partir da posse desta coleção "[...] é ser reconhecido e ter possibilidade de aprender mais sobre suas origens, pois este templo foi criado para transmitir mensagens, que fragmentadas limitam qualquer população de conhecê-las” (PIRES, 2017, p. 78).

\footnotetext{
${ }^{7}$ Acervo digital. Disponível em http://www.theacropolismuseum.gr/en/content/museum-history. Acesso em: 09 dez. 2017.
} 


\section{Egito}

Outro país que possui um histórico - ainda que recente - em relação à devolução de seus bens culturais é o Egito. Lá, o debate teve início a partir de 2002, quando o arqueólogo egípcio Zahi Hawass assumiu o cargo de Secretário geral do Conselho Supremo de Antiguidades do país (atual Ministério de Estado das Antiguidades). Na época, ele iniciou um intenso debate veiculado pela mídia sobre a devolução de alguns artefatos considerados ícones da história egípcia antiga, como o busto da rainha Nefertiti, que atualmente se encontra no Neues Museum, na Alemanha; a Pedra de Rosetta, exibida pelo British Museum, na Inglaterra; e o Zodíaco de Dendera, adquirido pelo Louvre, na França. Na verdade, o pedido de devolução do busto de Nefertiti remonta ao final dos anos de 1920, por iniciativa do egiptólogo francês Pierre Lacau, que dirigia o Serviço de Antiguidades naquele período (IKRAM, 2011). Ainda assim, a Alemanha sempre negou o seu retorno.

A partir das declarações de Zahi Hawass, muitos questionaram sobre a inviabilidade de retorno da maioria das peças, como se os seus apelos se estendessem a todos os acervos que atualmente se encontram em territórios estrangeiros, o que não é verídico:

Depois de 1983, tornou-se ilegal qualquer antiguidade deixar o Egito (e esse é o nosso foco). Antes havia um comércio ilegal de antiguidades. Também estamos pedindo o retorno de tudo o que foi retirado da parede de um monumento, mesmo se isso foi feito antes de 1983 (a menos que ele tenha sido esculpido no século XIX). Os acordos da UNESCO de 1970 cobrem isso. Sempre que há documentação suficiente para mostrar que a peça estava in situ e está agora na posse de um museu ou colecionador particular, exigimos o retorno dessas peças (HAWASS, 2002-3, p. 19, tradução nossa).

O ano de 1983 é considerado um marco, pois foi publicada no Egito a Lei n. 117, que estipula regulamentações para a proteção e a retirada das antiguidades que se encontram em seu território. Após inúmeras discussões, a lei foi revisada e alterada pela Lei n. 3 de 2010, que apresenta uma introdução escrita pelo próprio arqueólogo. Embora o Egito possua um histórico sobre medidas normativas para a proteção de seu patrimônio cultural, essa lei ainda se encontra em vigência.

$\mathrm{Na}$ tentativa de reunir esforços para solucionar os problemas de repatriação, em 2010 foi organizado no Cairo o evento intitulado Cooperação Internacional para a Proteção e a Repatriação do Patrimônio Cultural, que reuniu representantes de mais de vinte países, notadamente os interessados pela devolução de bens culturais, além de integrantes do Serviço de Imigração e Alfândega dos Estados Unidos. No entanto, países como a Alemanha, a França e a Inglaterra não fizeram parte da conferência. 
$\mathrm{Na}$ ocasião, os presentes puderam apresentar uma Lista de Desejos (Wish List), composta pelos principais objetos que gostariam que retornassem aos seus territórios originais. Cabe mencionar que é preciso distinguir a forma como esses objetos saíram de seus territórios em diferentes momentos da história, seja através de doação, de compra, de legado ou mesmo de saques e de pilhagens. Por isso, a cooperação de órgãos como a ONU (Organização das Nações Unidas), a UNESCO (Organização das Nações Unidas para a Educação, a Ciência e a Cultura), o ICOM (Conselho Internacional de Museus) e o ICOMOS (Conselho Internacional de Monumentos e Sítios) são fundamentais para a condução do debate em torno dos bens culturais.

Um dos principais argumentos utilizados para não repatriar as coleções egípcias está centrado na acusação do país não possuir condições necessárias para promover a conservação e a preservação dos objetos materiais. Pensando nisso, o Egito recebeu inúmeros investimentos destinados à construção do Grande Museu Egípcio, previsto para ser inaugurado no final de 2020. Esse empreendimento contará com amplos espaços para receber exposições permanentes e temporárias, uma biblioteca, um centro de pesquisa, laboratórios de restauração e pequenos museus destinados às crianças e às pessoas com deficiência, além de parques, jardins, loja e restaurantes. A aposta é que o seu Centro de Conservação GEM seja o maior do Oriente Médio ${ }^{8}$.

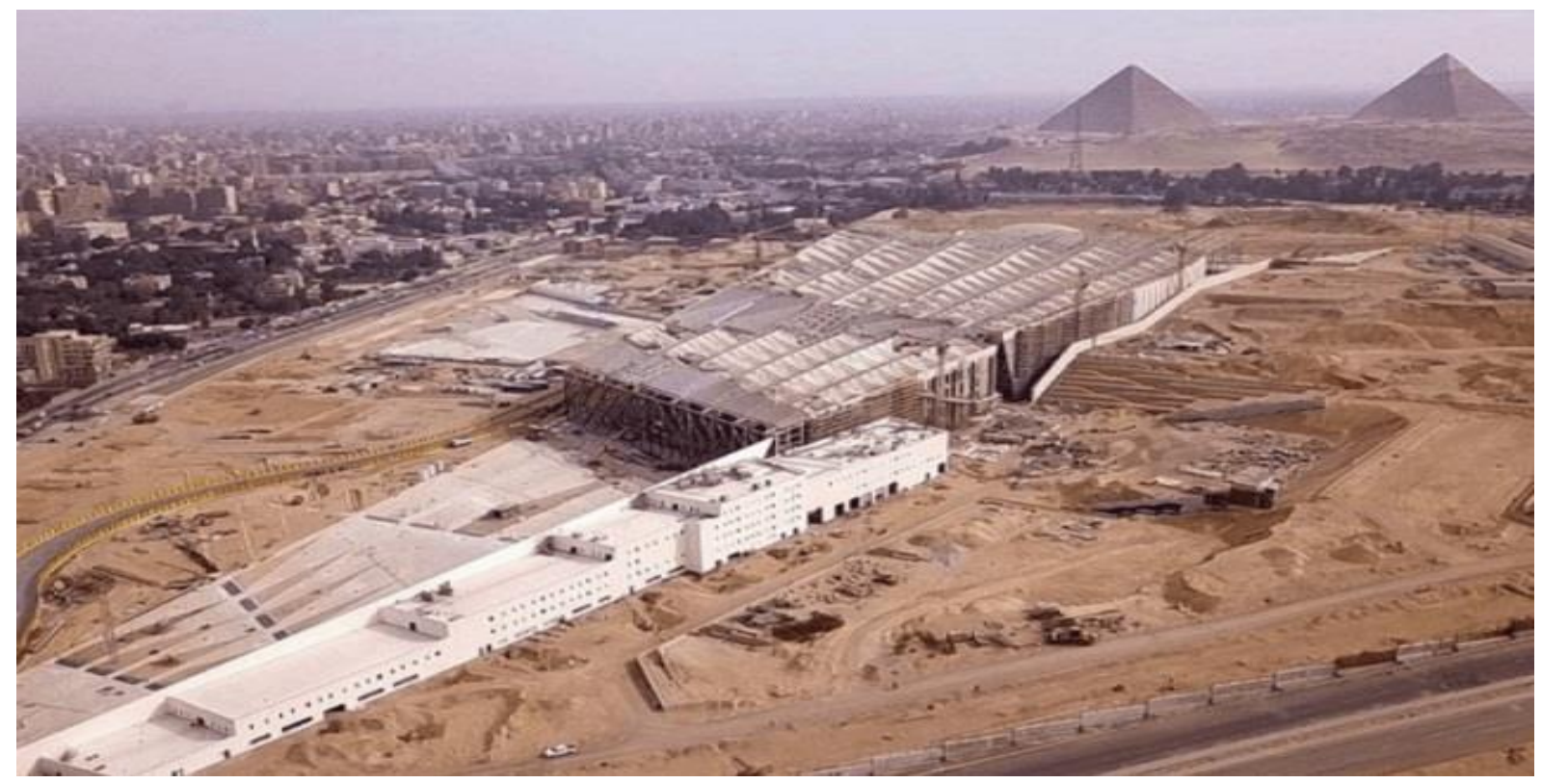

Figura 2 - Grande Museu Egípcio (GEM).

Fonte: Acervo Digital ${ }^{9}$.

\footnotetext{
${ }^{8}$ Informações disponíveis no site do museu: http://www.gem.gov.eg/ Acesso em: 20 dez. 2019.

${ }^{9}$ Disponível em: https://www.descobriregipto.com/tesouros-de-tutankhamon-em-espetaculo-holografico/. Acesso em: 23 dez. 2019.
} 
A iniciativa por parte da Grécia e do Egito em criar grandes museus e centros de pesquisa é uma resposta direta aos museus europeus que negam a devolução dos objetos, especialmente os que ainda estão amparados pela ideia de "falta de segurança" desses países. Isso porque uma breve pesquisa indicará uma infinidade de casos em que instituições museais, prédios e acervos históricos foram comprometidos, danificados ou totalmente destruídos, seja por acidentes ou mesmo fatalidades, e em diferentes regiões do mundo.

Além da construção desse novo museu e da renovação dos que já existem, o Egito está investindo em atividades que promovam a conscientização da comunidade em relação ao seu patrimônio cultural através de centros especializados que oferecem cursos, oficinas e palestras, como o "Centro de Egiptologia Zahi Hawass", inaugurado em 2018 em parceria com a Biblioteca de Alexandria.

\section{Caminhos possíveis para a cooperação entre os museus}

A partir da apresentação desses dois casos distintos e das sucessivas negativas de devolução das coleções por parte do Museu Britânico (assim como os demais museus que possuem acervos estrangeiros) podemos presumir que a repatriação não será viável, ao menos nos exemplos em questão.

Uma solução gradual seria o desenvolvimento de políticas de preservação eficientes para seus acervos e instalações adequadas para manutenção destes artefatos pelos países que solicitam. Desta forma, as restituições e repatriações deveriam ocorrer se desejadas pelas culturas de origem. Uma mudança desejável, que poderá ocorrer lentamente, sendo um processo influenciado pela “[...] dinâmica de conflitos, acordos políticos e convenções diplomáticas que causam uma situação de avanços e retrocessos, onde se torna quase impossível fazer previsões do futuro destas coleções" (PIRES, 2017, p. 79). Sendo assim, quais seriam as alternativas possíveis e viáveis para esse impasse atualmente?

Uma das respostas para essa indagação pode ser encontrada na utilização de réplicas como parte dos acervos museológicos, ideia essa que ainda é bastante questionável pelas instituições, especialmente se pensarmos no valor de autenticidade inerente aos objetos que compõem uma coleção, pois essa sugestão recai em um ponto crucial: a disputa pelas peças autênticas. De acordo com Chaumier ([s.a], p.3):

O objeto de museu carrega a marca da autenticidade de coisa verdade. O substituto que pode representar a reprodução se opõe ao objeto autêntico. [...]. Se o que querem dizer é o primordial, o substituto pode ser essencial. Mesmo se são raros, 
certos museus cujas coleções são compostas a partir de substitutos, são ou não museus? Segundo os critérios que questionamos, a definição varia.

Nesta perspectiva, a questão primordial é a relação de poder e responsabilidade que está estipulada para quem tem a guarda do patrimônio categorizado como mundial.

A problemática da autenticidade tem sido abordada por diferentes autores, embora seja "[...] sintomático o próprio fato de que poucos têm sido os estudos produzidos com a intenção de pensá-la como um problema; e muitos os que a tomam como um dado existencial ou histórico" (GONÇALVES, 2007, p. 118). Para o antropólogo José Gonçalves (2007, p. 124), essa negativa à problematização da autenticidade também integra uma "estratégia retórica", que está no cerne da formação das identidades nacionais.

Embora essa questão ainda crie uma grande tensão atualmente, encontramos exemplos de museus que recorram ao emprego das réplicas como parte de seus acervos institucionais, como o Museu de História da Arte (MuHar), situado em Montevidéu, no Uruguai e o Museu Ernesto de Cárcova, em Buenos Aires, Argentina. A narrativa expográfica do MuHar apresenta a história da arte mundial a partir de acervos formados por objetos originais e réplicas confeccionadas a partir dos modelos primários, inclusive itens da coleção dos Mármores do Parthenon e peças egípcias ${ }^{10}$. Dentre as réplicas mais famosas referentes à história da arte mundial, destacamos a Vitória de Samotrácia e a Vênus de Milo, que atualmente estão no Museu do Louvre; o busto de Nefertiti; e o Discóbolo, do escultor grego Míron, que possui inúmeras cópias em vários museus, já que o seu original foi perdido. Estas instituições tiveram sua origem a partir das Escolas de Belas Artes de seus países, no Brasil, o Museu de Belas Artes, anteriormente Escola de Belas Artes, no Rio de Janeiro, tem predominantemente réplicas do Museu do Louvre e do Museu do Vaticano.

O próprio Museu Britânico possui um programa diário que realiza experiências sensoriais com os seus visitantes. Intitulado Object handling sessions: Hands On desks (Sessões de manipulação de objetos: mãos nas mesas), teve início em janeiro de 2000, e proporciona aos visitantes o manuseio de réplicas dos objetos das suas coleções, acompanhados por mais de noventa voluntários ${ }^{11}$.

Em casos distintos, muitos museus recorrem às réplicas como recursos de acessibilidade para um público específico; como um instrumento lúdico para crianças e

\footnotetext{
${ }^{10}$ Para maiores informações sobre o histórico da instituição e de seus acervos, consulte o site do museu: http://muhar.montevideo.gub.uy/ Acesso em: 23 dez. 2019.

11 Disponível em: https://www.britishmuseum.org/pdf/Hands\%20On\%20Report\%20online\%2030-12-2010.pdf. Acesso em: 19 novembro 2018.
} 
jovens; ou como uma ferramenta educacional para recriar ambientes (como biomas e dioramas) e representar animais ou elementos que não existem mais.

No Brasil, o Museu de Arqueologia Ciro Flamarion Cardoso, localizado na cidade de Ponta Grossa, no Paraná, possui um acervo composto majoritariamente por réplicas que apresentam a história da civilização egípcia antiga e da América pré-colombiana. As peças do acervo são produzidas pelo próprio diretor do museu, o arqueólogo Moacir Elias Santos, a partir de moldes originais (COSTA, 2013).

Essas instituições apresentam uma característica em comum: o seu viés didático, que através da elaboração de programas educativos visam uma aproximação do público visitante com a história e a cultura de sociedades distintas. A partir desse enfoque, eles cumprem uma das principais funções dos museus: a comunicação e a difusão do conhecimento. Embora a utilização de réplicas como parte integrante dos acervos institucionais ainda não seja tão difundida e aceita por todos os museus, através dos exemplos que elencamos percebemos a sua importância como uma metodologia alternativa quando o acesso aos originais não é viável. Todavia, resta saber se essa metodologia estará disponível apenas para as localidades que reivindicam o retorno de seus bens culturais.

Como vimos, ainda há muito a ser discutido sobre a função social dos museus na conjuntura atual e as reparações históricas necessárias. A cada dia novos países reivindicam seus patrimônios culturais, demonstrando a incoerência da presença de seus objetos materiais em contextos estrangeiros, especialmente quando essa presença não é totalmente explicitada pela sua instituição de guarda.

Desta forma, em uma primeira aproximação com esta temática já é possível visualizar a complexidade do panorama da repatriação dos bens culturais, pois cada caso é único e apresenta um determinado contexto histórico, social, político e um conjunto de outras especificidades. Assim, poderíamos definir que cada caso deveria ser analisado individualmente, contudo, na maioria das vezes, as soluções dificilmente agradarão ambas as partes (COSTA, 2019; PIRES, 2017). No entanto, acreditamos que esse debate se desenvolve em um momento importante na história dos museus e na construção dos patrimônios culturais, para que possamos refletir sobre um quadro mundial da distribuição dos acervos museológicos e a importância dos discursos construídos e reverberados por essas instituições. 


\section{Referências}

BRUNO, M. C. O. Museologia e museus: os inevitáveis caminhos entrelaçados. Cadernos de sociomuseologia, v. 25, $\mathrm{n}^{\mathrm{o}} \quad 25, \quad$ p. 5-19, 2006. Disponível em: http://revistas.ulusofona.pt/index.php/cadernosociomuseologia. Acesso em: 28 dez. 2019.

CHAUMIER, S. O que define um objeto de museu?. In: L'objet de musée. Tradução: Thelma Palha.[s.a], p. 1-12. (Capítulo de Livro)

COSTA, K. L. Acervo de réplicas e seu papel educativo no Museu de Arqueologia Ciro Flamarion Cardoso (Ponta Grossa- PR). 2013. 68 f. Trabalho de conclusão de Curso (Graduação em Museologia) - Faculdade de Biblioteconomia e Educação, Universidade Federal do Rio Grande do Sul. 2013. (Trabalho de Conclusão de Curso)

COSTA, K. L. Caminhos para a descolonização dos museus: a questão da repatriação das antiguidades egípcias. 2019. 300 f. Tese (Doutorado em História) - Programa de PósGraduação em História, Universidade Federal de Santa Catarina. 2019. (Tese)

CURY, M. X. Exposição: concepção, montagem e avaliação. São Paulo: Annablume, 2005. (Obra Completa)

DOHMANN, M. A experiência material: a cultura do objeto. Rio de Janeiro: Rio Books, 2013. (Obra completa)

FERREIRA, L. M. Patrimônio arqueológico, pós-colonialismo e leis de repatriação. In: FUNARI, P. P. A.; PELEGRINI, S.; RAMBELlI, G. (Orgs.). Patrimônio cultural e ambiental: questões legais e conceituais. São Paulo: Annablume, 2009. v. 1, p. 67-85. (Capítulo de Livro)

GAY, A. La restitution des biens culturels à leur pays d'origine. Un débat au carrefour entre le droit, la politique et la morale. 2013. 67 f. Dissertação (Direito, Política e Moral) - Institut d'Études Politiques de Lyon, Université lumière Lyon 2, Lyon, 2013. (Dissertação)

GESTÃO DO PATRIMÔNIO MUNDIAL CULTURAL. Brasília: UNESCO Brasil, IPHAN, 2016. 163p. [Manual de referência do patrimônio mundial].

GONÇALVES, J. R. S. Antropologia dos objetos: coleções, museus e patrimônios. Rio de Janeiro, 2007. (Obra completa)

GUARNIERI, W. R. C. Bem e patrimônio cultural. In: BRUNO, M. C. O. (Org.). Waldisa Rússio Camargo Guarnieri: textos e contextos de uma trajetória profissional. V.1. São Paulo: Pinacoteca do Estado: Secretaria do Estado da Cultura: Comitê Brasileiro do Conselho Internacional de Museus, 2010. p.119 -122. (Capítulo de Livro)

GUARNIERI, W. R. C. Conceito de Cultura e sua inter-relação com o patrimônio cultural e a preservação. In: BRUNO. M. C. O. (Coord.). Waldisa Rússio Camargo Guarnieri: textos e contextos de uma trajetória profissional. São Paulo: Pinacoteca do Estado: Secretaria de Estado da Cultura: Comitê Brasileiro do conselho Internacional de Museus, 2010. V. 1. P. 7885. (Capítulo de Livro) 
HAWASS, Z. Recovering Egypt's Stolen Treasures. KMT: A Modern Journal of Ancient Egypt. Sebastopol: KMT Communications, vol. 13, n. 4, p. 19-24, 2002-3. (Artigo em Periódico Físico)

IKRAM, S. Collecting and Repatriating Egypt's Past: Toward a New Nationalism. In: SILVERMAN, H. (Ed.). Contested Cultural Heritage: Religion, Nationalism, Erasure and Exclusion in a Global World. New York: Springer, 2011. p. 141-154. (Capítulo de Livro)

MENESES, U. B. A problemática da identidade cultural nos museus: de objetivo (de ação) a objeto (de conhecimento). Anais do Museu Paulista: História e Cultura Material, v. 1, n. 1, p. 207-222, 1 jan. $1993 . \quad$ Disponível em: http://www.revistas.usp.br/anaismp/article/view/5282/6812. Acesso em: 23 dez. 2019. (Artigo em Periódico Digital)

PEARCE, S. M. Museums, Objects and Collections: a cultural study. Washington D.C.: Smithsonian Institution Press. 1992. (Obra completa)

PIRES, K. T. A. A defesa de uma presença: A disputa pela repatriação dos Mármores do Parthenon. 2017. 86p. Trabalho de conclusão de Curso (Graduação em Museologia) Faculdade de Biblioteconomia e Educação, Universidade Federal do Rio Grande do Sul. 2017. (Trabalho de Conclusão de Curso) 